\title{
Religiosity, Social Support, and Health among the Elderly in Kuwait
}

\author{
Yagoub Y. Al-Kandari, Ph.D.
}

Kuwait University

\begin{abstract}
The aim of this study is to determine whether there is a relationship between religiosity, social support, and health among the elderly in Kuwaiti society. Data was collected from 1472 adults over the age of 60 years old by trained nurses. Interviews were held with the help of the closest person to the participant at home. Sociocultural, demographic information and other variables were used. Data show that the respondents with a high degree of religiosity had high social support from their friends and relatives, more frequency of contact, and more strength in their relationships with them. The data also show that the respondents with a high degree of self-reported religiosity have a lower mean of systolic and diastolic blood pressure measurements than did the respondents with a low degree of religiosity. The results show the impact of the degree of religiosity on the elderly's daily life and well-being.
\end{abstract}

Keywords: Religiosity and Health in Kuwait, Elderly health-Kuwait, Social Support and elderly-Kuwait.

\section{Introduction}

Several studies discuss the relationship between both social support and religiosity with health. Some concentrate on the association of social support and religiosity on psychological impairment, such as depression and anxiety, which is considered to be one of the most essential factors of somatic symptoms. On the whole, they have found that social support and religiosity can buffer one against anxiety and depression. Other studies also showed that both social support and religiosity have a major effect on one's quality of life (e.g., Lim \& Yi, 
2009; Thomas, 2002) and serve as a protective factor against suicide, as shown among one ethnic group in Wingate and colleagues' (2005) study.

Researchers have also examined the relationship between religiosity and general health status and compromising behaviors and illness in different populations and societies. According to King's (1990) review of the literature, religiosity is associated with healthy behavior and longevity. Oleckno and Blacconiere (1991) found a positive relationship between religiosity and wellness and a negative association with illness. Chida, Steptoe, and Powell (2009) reported that religiosity lowers the mortality rate in many population studies. According to Childa and Steptoe (2008), religiosity has an effect on one's positive psychological well-being, which in turn "has a favorable effect on survival in both healthy and diseased populations" (p. 741).

To examine the relationship between religiosity and some chronic diseases, King's (1990) literature review revealed that religious beliefs and practices have a positive relationship with human health in general, and that religiosity reduces systolic and diastolic blood pressure. There is strong evidence which indicates that religiosity is directly linked to physiological processes, including blood pressure and cardiovascular diseases (Seeman, Dubin, \& Seeman, 2003). Levin and Vanderpool (1989) reviewed 20 empirical research literatures concerning the relationship between these two variables. They concluded that "characteristics and functions of religion have salutary effects on blood pressure" (p. 76). A study conducted among the Kuwaiti population found the same results: people who are more religious suffer less from hypertension (AlKandari, 2003). In Malaysia, another Muslim society, Momtaz, Hamid, and Yahaya (2009) found that general chronic health problems are moderated by religiosity.

On the other hand, there is a need to draw attention to the many studies that show no relationship between religiosity and physical and mental health (e.g., Bergin, 1987; Blazer \& Erdman, 1976; Blumenthal et al., 2007; Campbell, Philip, \& Willard, 1976; Hadaway, 1987; Holt, Clark, \& Klem, 2007; Lewis, Lanigan, Joseph, \& Fockert, 1997; Lewis, Maltby, \& Burkinshaw, 2000). It is well reviewed that religiosity has a positive relationship with happiness and wellbeing (e.g., Abdul-Kalek, 2006; Francis, 2004; Robbins \& Francis, 1996). On the other hand, Lewis and colleagues $(1997 ; 2000)$ showed no direct relationship. In studies with undergraduate students, one showed a significant relationship between religiosity and happiness (Robbins \& Francis, 1996); another showed no relationship (Lewis, 1997); and another study showed only a small relationship (Francis, 2004).

Other studies used multidimensional measurements and included spiritual experiences, frequency of religious attendance, and frequency of prayer and did not show a relationship between these and physical health outcomes (e.g., Blumenthal et al., 2007). Some studies showed no relationship between 
religiosity and depression (Bergin, Masters, \& Richards, 1987; Nelson, 2002), general well-being (Francis, Jones, \& Wilcox, 1997; Koenig, Siegler, \& George, 1989), or obsessive-compulsive disorders (Assarian, Biqam, \& Asqarnejad, 2006). Crawford and colleagues (1989) found no relationship between religiously and health. For example, no association was found between religiosity and mental health/distress among men. Robbins and Francis' (1996) findings supported the argument that the differences and variations in studies may relate to the measurement of the religiosity employed. Despite these differences, most studies showed a clear association between religiosity and general health (Abu-Raiya \& Pargament, 2007; Moreira-Almeida, Neto, \& Koenig, 2006).

For elderly individuals, many empirical studies discussed the positive effect of religion on health. Religious attendance and involvement, faith, and practice have been shown to have a positive effect on older people's well-being. Research has shown that religiosity may be associated with lower mortality rate among this social stratum. This has been discussed and clarified in a wide range of studies in different cultures and societies (e.g., Arcury, Stafford, Bell, Golden, Snively, \& Quandt, 2007; Braam, Hein, Deeg, Twisk, Beekman, \& Van Tilburg, 2004; Reyes-Ortiz, Pelaez, Koenig, \& Mulligan, 2007; Yeager, Glei, Au, Lin, Sloan, \& Weinstein, 2006). Researchers have shown that religiosity works as a protective factor (Musick, House, \& Williams, 2004; Oman \& Reed, 1998; Oman, Kurata, Strawbridge, \& Cohen, 2002). Oman and Reed (1998) integrated religiosity and social support to explain their protective effect on one's health. The researchers stated that "a person who [attends] religious services [has] lower mortality than those who [do] not" (p. 1469). Religiosity plays an important role for older adults who are ill or hospitalized. Some studies (Hebert, Dang, \& Schulz, 2007; Koenig, 1998, 2007; Yohannes, Koenig, Baldwin, \& Connolly, 2008) found a direct relationship between religiosity and psychological and physical diseases and illness in older adults, while other studies found this relationship, especially with depression, is complex and depends on the type of religion one is practicing (King, Lyness, Duberstein, He, Tu, \& Seaburn, 2007). Another study found that religiosity moderates the chronic diseases (Momtaz et al., 2009). To examine the differences between two ethnic groups, Cummings, Neff, and Husaini (2003) reported that older African Americans have a higher level of social support and religiosity than white Americans, and a lower level of depression. For patients with coronary heart disease at a mean age of 61, Hughes and colleagues (2004) found that religiosity and social support play major roles to buffer against anxiety and distress. Another study (Yoon, 2006) examined differences among three different ethnic groups (Native Americans, African Americans, and Korean Americans). It found that Native Americans used more religious coping skills than the other two groups. 


\section{Measuring Religiosity}

Abdel-Khalek (2007) and Abu-Raiya and Pargament (2010) reviewed some studies that discussed religiosity assessments. Religiosity can be assessed by behavior aspects such as frequency of religious attendance, or by attitudinal measurements. Many empirical studies measure Islamic religiosity using different scales. For example, "alexithymia, emotional intelligence, self-consciousness, and physiological adjustment" (Ghorbani \& Watson, 2006), strength of faith (Mussap, 2009), beliefs and practice (AlMari et al., 2009; Jana-Masri \& Priester, 2007), knowledge (Alghorani, 2008), attitudes and values (Francis et al., 2008), and worldview (Wilde \& Joseph, 1997) of Islam were used by different and multi-dimensional scales.

Using a single item self-rating scale is another dimension of measuring religiosity. Abdel-Khalek (2007) and Abu-Raiya and Pargament (2010) reviewed some studies that concentrated on a single item to measure religiosity. In his study of a sample of Arab Muslims, Abdel-Khalek (2007) concluded that a selfrating of religiosity (SRR) "based on a single-item measure demonstrated good temporal stability, concurrent validity, and factorial validity” (p. 213-14). After reviewing 14 studies using a single scale item, Abu-Raiya and Pargament (2010) stated that "the findings of this line of research have been largely consistent" ( $\mathrm{p}$. 3). Many local studies used the self-rating religiosity scale in correlation with some variables (Abdel-Khalek, 2002, 2006, 2007a, 2007b, 2008; Abdel-Khalek \& Lester, 2009; Abdel-Khalek \& Maltby, 2008; Baroun, 2006).

\section{Religious Studies in Kuwait}

Few studies discussed the relationship between religiosity and health in Kuwait. Some studies discussed the relationship between religiosity and health status in adolescent and middle-aged personnel. Most concentrated on and discussed the psychological concepts. Some studies discussed the relationship between religiosity and death anxiety, obsession, and distress (Abdel-Khalek \& Lester, 2009; Abdel-Khalek, 2002; Abdel-Khalek \& Maltby, 2008; Lester \& AbdelKhalek, 2008). Among Kuwaiti college students, no relationship was found between death anxiety and religious motivation scale, self-rating of religiosity, and strength of religious belief (Abdel-Khalek \& Lester, 2009). Other studies of adolescents used self-rating and motivation scales to show a significant negative correlation between anxiety and religiosity (Abdel-Khalek, 2002; Baroun, 2006). Others discussed the relationship between religiosity and physical health, mental health, and happiness, concluding that middle-aged personnel consider religiosity an important element in Kuwaiti life (Abdel-Khalek, 2008). The same was true for those in the adolescent sample. There was a correlation 
between religiosity motivation and physical health, mental health, happiness, and life satisfaction (Baroun, 2006).

Religiosity was found to be related to happiness and health in other studies conducted in two different sample groups, undergraduate college students (Abdel-Khalek, 2006) and secondary school students (Abdel-Khalek, 2007). In examining a relationship between religiosity and hypertension in a selected Kuwaiti sample, Al-Kandari (2003) found that religious commitment and religious activities have an effect on systolic and diastolic blood pressure. Being involved in Islamic organizations and engaging in religious activities were major contributors to health. Religiosity provided more security and social support, which had a direct relationship to people's health status.

To examine the properties of two instruments related to Islamic attitudes and moral values among young adults in the secondary school in Kuwait, Francis, Sahin, and Failakawi (2008) found that these instruments have "internal consistency reliability and construct validity" (p.9). Other health studies found a significant relationship between religiosity and the well-being of traumatized males and females (Ridah, 2009), obesity (Al-Kandari, 2007b), and fertility rates (Adal, 2001). Differences were found between Muslim Sunni and Muslim Shi' ite concerning fertility rates in Kuwait society (Muslim Sunnis have higher fertility rate compared with Muslim Shi'ites; Al-Kandari, 2007a).

To the author's knowledge to date, there are no studies that discuss the relationship between religiosity and health status among the elderly in Kuwaiti society. The major aim of the current study is to determine whether there is a relationship between religiosity, social support, and health among the elderly in Kuwaiti society. The major indicators of health status that we investigated included systolic and diastolic blood pressure, somatic symptoms, and health self-rating. This study was funded by a larger project supported by Kuwait University.

\section{Methodology}

\section{Participants and Procedures}

The participants in the research project included 1,427 elderly adults over 60 years old from a total of 1,571 (472 men and 955 women) receiving care from six home care units in six governorates related to the Ministry of Social Affairs in Kuwait. The average age was 77.12 years $(S D=9.41)$. Some $(141)$ of the residents were excluded from this study because they were out of Kuwait during data collection, while others were under sixty years old. The respondents came from different sociocultural backgrounds, since home care units in all six governorates are governmental services provided to all elderly Kuwaitis. 
The data were collected during a regular visit by the unit team. For data collection, well-trained Research Assistants (RAs) who are nurses and working in these units collected the physical and cultural data after getting permission from both the department heads and the respondents whom the RAs knew well. They collected data during regular monthly visits. They usually took some medical measurements such as blood pressure, blood glucose, pulse, and noted general physical characteristics. Interviews were held with the help of the closest person to the participant at home, someone who knew his/her health status and social and cultural information. Interviews were held in front of the elderly participants, and they confirmed the answers. RAs ensured the validity of these answers through the agreements of both of them, representative and elderly participant. The answers were taken from respondents directly. The closest person helped to confirm the validity of the answers since he/she is familiar with the respondents' health status. Because of the nature of the sample, sometimes, the closest person helped to clarify questions to the respondents. The procedures were usually carried out in the evenings during regular visits, usually at six and seven p.m., before dinnertime.

\section{Measures}

This study used a combination of sociocultural and biological variables. Sociocultural and demographic information and other variables were gathered from the participants' family members through home interviews for the project. Many scales were used in this study, as follows:

1. Self-rating scales: Three self-rating scales were used in this study for religiosity, general health, and general health in the last year:

- Self-rating scale of religiosity: What is your level of religiosity in general?

- Self-rating scale of general health: What is your estimation of your health in general?

- Self-rating scale of health in the last year: What is your estimation of your health in the last year?

A ten-point scale was used from 0 to 10 . The respondents were asked to circle the number to describe their feelings concerning their religiosity and health. For religiosity, the lowest score (0) was not religious at all, and the highest score (10) was very religious. For health, the lowest score (0) was feeling poor and the highest score (10) was feeling excellent. Self-rating scales have been used in many studies to show validity. For example, and as mentioned above, the self-rating scale of religiosity shows "good temporal stability, concurrent validity, and factorial valid- 
ity" (Abdel-Khalek, 2007; pp. 213-14). As Abdel-Khalek (2006) stated, "although there are Western-developed inventories to measure religiosity, they are based on the Christian concept of God. It is not yet known whether these inventories are valid for Islamic conceptions" (p. 541). A two week test-retest reliability of these self-rating scales were (.91) for self-rating of religiosity, (.89) for general health self-rating, and (.92) for self-rating in the last year scales.

2. Social Support Scale (SSS). A scale was developed by Zimet and colleagues (1988) and modifications were made to satisfy the sample. This scale was used also for the elderly in another study (Yoon, 2006). This scale has been used in other studies in Kuwait (Al-Kandari, 2001a; AlKandari, 2001b; Al-Mutiri, 2000). Some modifications have been made in the scale to fit the elderly adults who constitute our sample. The overall scale contained 12 sentences, to which the participants' family members responded using a six-point scale, from strongly agree (6) to strongly disagree (1). The respondents' family members were asked about the elderly person's social support status. The scale includes sentences such as: "There is a special person who is around her/him when s/he is in need", "There is a special person with whom s/he can share her/his joys and sorrows", "Her/his family really tries to help her/him", "S/he gets emotional help and support s/he needs from her/his family", "His/her friends really try to help her/him", and "S/he has a special person who is a real source of comfort to her/him". This scale has been shown to have high internal consistency overall (alpha coefficient of 0.87 ).

3. Frequency of Contact and Strength of Contact scales. The respondents were asked about kin and friends' frequency of contact with their elderly family member in daily life. Spouse, children, cousins, close friends, and others were included in this scale. In addition, the strength of relations with these people was used as another social support scale. The participants were asked "How usually do you contact: spouse, children, cousins, close friends ... " Also, they were asked "What is the strength of your relationship with your spouse, children, cousins, close friends .... A five-point scale was used for both of these scales: from always (5) to never (1). Also, these two scales have been shown to have high internal consistency overall (alpha coefficient of 0.84 and 0.85 , respectively).

4. Somatic Symptoms Inventory (SSI): SSI was developed by AbdelKalek (2003b) and has been used to examine the physical health status of the respondents. In SSI, "the vast majority of items [are] related to physical and organic aspects, e.g., tooth aches, dyspnea, gastric upset, joint 
pains, and otitis, notwithstanding that it is difficult to differentiate the psychic from the somatic" (p. 117). This inventory included sixty somatic symptoms. A four-point Likert-type rating scale was used: $0=$ None, $1=$ Some, 2 = Much, and 3 = Always. This inventory has been used in other studies with the elderly in Kuwait as well (Abdel-Kalek, 2003a, 2004; Al-Kandari, 2001a). It has been shown to have high internal consistency overall for the sample in the current study (alpha coefficient of 0.92).

5. Blood Pressure (BP). BP measurements were taken by the nurse RAs using an aneroid sphygmomanometer (desk model). Both systolic and diastolic readings were taken. Systolic pressure was read as the first Korotkoff phase or the onset of sound. Diastolic pressure was read as the fifth Korotkoff phase or complete disappearance. After approximately $10 \mathrm{~min}$ utes of relaxation and while visiting, the subjects were asked to be seated if they were able, with their arm supported at heart level. Three blood pressure measurements were taken at different times during the visit. The average of these three readings was recorded and used as one of the major dependent variables in the analysis.

\section{Results}

When the degree of religiosity was divided into three categories (low, medium, and high), there was a significant difference between religiosity and the social support variables in general, as shown in Table 1 . The data showed that the respondents with a high degree of religiosity had high social support from their friends and relatives, more frequency of contact, and more strength in their relationships with them. The data showed the lowest mean with the lower self-reported degree of religiosity, which was clear in the social support score, frequency of contact score, and the strength of relationship score.

For health variables, the data in Table 2 show clear significant differences between the degree of religiosity and systolic and diastolic blood pressure, somatic symptoms, and health self-report in general and in the last year. The data show that the respondents with a high degree of self-reported religiosity have a lower mean of systolic and diastolic blood pressure measurements than did the respondents with a low degree of religiosity. The respondents with a high degree of religiosity have a lower mean in the somatic symptom inventory compared with the low degree of religiosity. The results show that the higher the degree of religiosity, the lower the suffering from somatic symptoms. For health self-report in general and in the last year, the results show that a higher degree of religiosity leads to a higher mean in the satisfaction of health in general. 
TABLE 1. Differences between degree of religiosity in three cut-off categories: low, medium, and high by some health and social support variables (one-way ANOVA).

\begin{tabular}{lrrrr}
\hline Degree of Religiosity & Mean & SD & F Ratio & P Value \\
\hline Social Support Scale & & & & \\
$\quad$ Low & 44.39 & 7.97 & & \\
$\quad$ Med & 50.17 & 10.18 & 60.91 & 0.0001 \\
$\quad$ High & 51.87 & 9.33 & & \\
Frequency of Contact Scale & & & & \\
$\quad$ Low & 12.88 & 8.15 & & \\
$\quad$ Med & 21.48 & 9.72 & 119.05 & 0.0001 \\
$\quad$ High & 21.70 & 9.70 & & \\
Strength of Relationship Scale & & & & \\
$\quad$ Low & 13.06 & 8.66 & & \\
$\quad$ Med & 24.15 & 8.87 & 231.81 & 0.0001 \\
$\quad$ High & 25.64 & 9.09 & & \\
\hline
\end{tabular}

TABLE 2. Differences between degree of religiosity in two cut-off categories: low and high by some health and social support variables.

\begin{tabular}{lccc}
\hline Degree of Religiosity & Mean & SD & t-Value \\
\hline Systolic Blood Pressure & & & \\
$\quad$ Low & 155.83 & 19.00 & $1.67^{*}$ \\
$\quad$ High & 152.75 & 18.39 & \\
Diastolic Blood Pressure & 97.59 & 24.06 & $2.47^{\star}$ \\
$\quad$ Low & 95.17 & 10.75 & \\
$\quad$ High & & & \\
Somatic Symptom Inventory & 112.99 & 33.73 & $-2.24^{*}$ \\
$\quad$ Low & 107.38 & 22.41 & \\
$\quad$ High & 3.82 & 1.80 & $-20.76^{\star \star}$ \\
Health Self-Report & 6.84 & 1.65 & \\
$\quad$ Low & & & \\
$\quad$ High & 2.30 & 0.81 & -16.99 \\
Health Self-Report (Last Year) & 3.44 & 0.81 & \\
$\quad$ Low & &
\end{tabular}

To examine the relationship between these variables with the self-reported degree of religiosity, Table 3 shows that there is a significant relationship between the degree of religiosity and the social support scale, frequency of contact, strength of relationship, systolic blood pressure, diastolic blood pressure, and health self-report in general and in the last year. The data show that the higher the degree of self-reported religiosity, the higher social support the respondents have, and the more frequency of contact and strength of contact and relationships they have with their relatives and friends. Also, the higher the degree of religiosity, the lower the systolic and diastolic blood pressure measurements, and the higher the self-report about the respondents' general health and health in the last year. 
To explain whether health variables are predicted by religiosity or the predictive ability of religiosity on health outcome, coefficient regression was measured. Table 4 illustrates the result of the predicted variables by religion after controlling some other related variables.

The data show that the systolic and diastolic blood pressure, somatic symptoms, and health self-report in general and in the last year are predicted by and related with the religiosity. Religiosity is a predictor factor of these variables.

\section{Discussion}

The data show the association between of religiosity on the elderly's daily life and well-being in a Kuwaiti elderly population. Religiosity, as discussed and reviewed in many studies, is a significant factor for human health in all life stages, even during adolescence (see Rew \& Wong, 2006; Wong, Rew, \& Slaikeu, 2006), and becomes more important for the elderly because of rapid physiological change in that stage. Religiosity may provide a protective factor against disease and illness by providing the elderly with a feeling of calm, psychological comfort, security, and faith as suggested by other studies across different

TABLE 3. Correlation between religiosity and some social support scales, systolic and diastolic blood pressure, and health self-rating scales.

\begin{tabular}{lc}
\hline Variables & Correlation \\
\hline Social Support Scale (SSS) & $0.31^{\star \star}$ \\
Frequency of Contact & $0.33^{\star \star}$ \\
Strength of Relationship & $0.52^{\star \star}$ \\
SBP & $0.10^{\star}$ \\
DBP & $0.10^{\star}$ \\
Health Self-Scale Report & $0.57^{\star \star}$ \\
Health Self-Scale Report (last year) & $0.48^{\star \star}$ \\
\hline
\end{tabular}

* $P<0.05$

$\star * P<0.01$

TABLE 4. The regression coefficient of religiosity scale (independent variable) on health variables (dependent variables).

\begin{tabular}{lccc}
\hline \multicolumn{3}{c}{ Religiosity } \\
\hline Variables & B & Beta & t-Value \\
SBP & -.767 & -0.77 & $-2.30^{\star}$ \\
DBP & -0.06 & -0.04 & $-1.74^{\star}$ \\
SSI & -0.10 & -0.04 & $-5.62^{\star \star}$ \\
Health Self-Report & 0.177 & 0.233 & $11.44^{\star \star \star}$ \\
Health Self-Report (Last Year) & 0.140 & 0.040 & $1.77^{\star}$ \\
\hline
\end{tabular}

${ }^{*} p<0.05,{ }^{* *} p<0.01,{ }^{* \star *} p<0.001$ 
cultures and societies (e.g., Arcury, Stafford, Bell, Golden, Snively, \& Quandt, 2007; Braam, Hein, Deeg, Twisk, Beekman, \& Van Tilburg, 2004; Reyes-Ortiz, Pelaez, Koenig, \& Mulligan, 2007; Yeager, Glei, Au, Lin, Sloan, \& Weinstein, 2006). As Levin and Vanderpool (1989) stated, religious practices, rites, and belief systems have a psychological effect on an individual's health, especially blood pressure, which is related to other diseases in the human body.

Hypertension is related to cardiovascular diseases and is responsible for around one-third of all deaths in modern countries. Older people are more sensitive to hypertension and other chronic diseases, since they go through rapid changes in their physiological processes. The findings of the current study confirm the review by Koeing and colleagues (2001), who found that there is a clear association between religiosity and fewer symptoms of chronic diseases.

As confirmed by Chaaya, Sibai, Fayad, and El-Roueiheb (2007), religiosity is an important aspect in the life of the elderly in Arab countries in general. It is an important element in daily social and political life. That study reported that "religious practice is discussed as an indicator of social solidarity rather than an aspect of religiosity" (p. 37). The elderly are greatly respected in $\mathrm{Ku}$ waiti society, where they are afforded a higher social status than in the West (Mansour, 1987). They earn their social status and power from two essential sources: tradition and religion. As stated by many researchers (e.g., Al-Kandari, 2010; Barakat, 2008), a grandfather in the extended family in traditional Arab countries has control and power over his family. He is the head of his family. Religion provides a rule of respect and concentrates on the social ties for the elders. This high level of respect is especially encouraged by many of the Prophet Mohammed's words (hadith).

Because of the process of socialization, there is a direct relationship between children and parents in terms of the degree of religiosity. This may explain the tight relationship we found between the respondents' religiosity and their social support. The more religious elderly have the highest social support. This was discussed in another study of the general population in Kuwait, which used religiosity as a variable (Al-Kandari, 2003). The data of Al-Kandari's study show the importance of religiosity and social support in the lives of the elderly.

Several studies, including the current study, conclude that religiosity plays a major role in human life and well-being. The data in the current study show that the higher the degree of religiosity, the lower are the systolic and diastolic blood pressure measurements. This is supported by other studies conducted in different cultures, as well (Al-Kandari, 2003; Hixson et al., 1998; Steffen et al., 2001; Tartaro et al., 2005; Walsh, 1998). This finding may explain that religiosity acts as psychological support and points to the improvement in one's ability to cope with and protect against stress (Tartaro et al., 2005). As stated by Wulff (1997, p. 248), intrinsic religious orientation proved to be positively associated with life satisfaction, psychological adjustment, self-control, better personal- 
ity functioning, higher self-esteem, and greater sense of purpose in life. Other researchers found a negative association with intrinsic religious orientation for anxiety, death anxiety, neuroticism, depression, impulsivity, etc. (as cited in Abdel-Khalek, 2006). The findings of a large local study (Abdel-Khalek, 2007) conducted in Kuwait also confirms these findings, showing that religiosity is a predictor factor for anxiety, depression, happiness, mental health, and physical health.

As Shkolnik and colleagues (2001) stated, "the most significant factor influencing the subjects' life satisfaction was religiosity" (p. 201). Also, Seeman and colleagues (2003) stated that Judaic and Christian religious traditions provide a strong evidence of the effect of religiosity on human immune function.

The findings of this study confirmed the hypothesis that there is a direct positive relationship between religiosity and social, psychological, and physiological elements. We found that there is a relationship between self-rating of religiosity and social support, frequency of contact with friends and relatives, strength of contact with friends and relatives, systolic and diastolic blood pressure, somatic symptoms, and self-rating of general health in general and in the last year among the elderly.

We also need to note here that measuring religiosity in this study depends on a single self-rated item scale. Abu-Raiya and Pargament (2007) reviewed some studies that used a single item and found that it is "positively linked to desirable mental health and well-being indicators (e.g., happiness, optimism, satisfaction in life) and negatively tied to undesirable mental health and wellbeing indicators (e.g., anxiety, depression)" (p. 3). Although this scale shows this positively concerns mental health and well-being and has a good stability and concurrent and factorial validity, a single item scale must be viewed within the limitations related to its nature as stated by Abdul-Kalek (2007).

A single item self-rating scale of religiosity does not provide a complete understanding of one's religiosity. It does not show the real rituals, practices, beliefs, and expressions of someone's faith. It lacks measurement of attitudes or behaviors. For this sample, this scale does not measure the elderly's Islamic beliefs and practices, but measures the "overall intrinsic religiosity score," which shows validity as do many long scales discussed and used in other studies (e.g., Burisch, 1984, 2007; Abu-Raiya \& Pargament, 2007). This study is limited by its use of a single self-rating scale item which measures one's feelings about oneself concerning religiosity and relates this to other variables. For this reason, a multi-dimensional scale, which measures behaviors, beliefs, and attitudes, is necessary for further studies.

To get a better understanding of multi-dimensional measurements of religiosity, Holt, Haire-Joshu, Lukwago, Lewellyn, and Kreuter (2005) reviewed some studies that show several mechanisms of religiosity affecting health by getting involved in church activities considered as a behavior, practice, and belief 
of religion. They stated that "church is proposed to benefit health through advocating a healthy lifestyle, sanctions against negative health-related behaviors, social support, the experience of positive affect, and positive self-perceptions" (p .85). Multi-dimensional measurements of religiosity such as reading the Qu'ran, praying five times a day, getting involved in Islamic activities, carrying out additional Islamic practices, etc., have been studied in the general Kuwaiti population and show a significant relationship with health status and social support (Al-Kandari, 2003). Still, multi-dimensional measurement studies are needed, since only few have been conducted in Kuwait examining the role of religion in the elderly's health status.

Religiosity plays a vital role in human societies. Koenig and colleagues (2001) reviewed one hundred studies discussing the relationship between religiosity and well-being. They found that "seventy-nine of these 100 studies reported that religiosity was significantly related to higher life satisfaction, more positive affect, and greater happiness" (cited in Yeung \& Chan, 2007).

Religiosity and health self-satisfaction is another important research direction. Many other social and health aspects can be examined in a wide range of research in Kuwait, especially for the elderly. Abu-Raiya and Pargament (2010) listed several important topics with respect to the relationship between Islamic religion and health and well-being. Future research in Kuwaiti society can explore areas such as "the links between Islam and mortality, marital functioning, parenting practices, and spiritual well-being ...” (p. 16). Kuwaiti society is a fertile environment for a great deal of research in these areas.

\section{References}

Abdal, Y (2001). Determinants of fertility expectation in Kuwait: A pilot study regarding reproduction behavior of the students at Kuwait University. Journal of the Gulf and Arabian Peninsula Studies, 10(29), 45-68.

Abdel-Khalek A.M, and Naceur, F. (2007). Religiosity and its association with positive and negative emotions among college students from Algeria. Mental Health, Religion \& Culture, 10(2), 159-170.

Abdel-Khalek A.M, Maltby, J. (2008). The comparison of predictors of death obsession within two cultures. Death Stud, 32(4), 366-77.

Abdel-Khalek A.M. (2002). Age and sex differences for anxiety in relation to family size, birth order, and religiosity among Kuwaiti adolescents., Psychol Rep, 90, 1031-6.

Abdel-Khalek A.M. (2006). Happiness, health, religiosity: significant relations. Mental Health, Religion \& Culture, 9(1), 85-97.

Abdel-Khalek A.M. (2007a). Assessment of intrinsic religiosity with a single-item measure in a sample of Arab Muslims. Journal of Muslim Mental Health, 2, 211-215.

Abdel-Khalek A.M. (2007b). Religiosity, happiness, health, and psychopathology in a probability sample of Muslim adolescents. Mental Health, Religion \& Culture, 10(6), 571-83. 
Abdel-Khalek A.M. and Lester, D. (2007) Religiosity, health, and psychopathology in two cultures: Kuwait and USA. Mental Health, Religion \& Culture. 10(5): 537-550.

Abdel-Khalek AM \& Lester, D. (2009). Religiosity and death anxiety: no association in Kuwait. Psychol Rep, 104(3), 770-2.

Abdel-Khalek AM. (2008). Religiosity, health, and well-being among Kuwaiti personnel. Psychol Rep, 102(1), 181-4.

Abdel-Khalek, A.M (2004). Can Somatic Symptoms Predict Depression? Social Behavior and Personality, 32(7), 659-666.

Abdel-Khalek, A.M. (2003a). Can Somatic Symptoms Differentiate Anxiety from Depression? Alexandria Bulletin, No 3, 289-302.

Abdel-Khalek, A.M. (2003b). The Somatic Symptoms Inventory (SSI): Development, Parameters, and Correlates. Current Psychiatry, 10(1), 114-129.

Abdel-Khalek, A.M. (2006). Happiness, health, and religiosity: Significant relations. Mental Health, Religion, \& Culture, (9)1, 85-97

Abu-Raiya, H. \& Pargament, K (2010). Empirically based psychology of Islam: Summary and critique of literature. Mental Health, Religion, \& Culture, 1-23.

Alghorani, M.A. (2008). Knowledge-Practice Measure of Islamic Religiosity (KPMIR): A case of high school Muslim students in the United States. Journal of Muslim Mental Health, 2, 25-36.

Al-Kandari Y.Y. (2003). Religiosity and its relation to blood pressure among selected Kuwaitis. J Biosoc Sci, 35(3), 463-72.

Al-Kandari, Y. (2007a). Fertility and its relation with sociocultural factors in Kuwaiti Society. Eastern Mediterranean Medical Journal, 13(6): 1364-1371.

Al-Kandari, Y. (2007b) Prevalence of Obesity in Kuwait and its Relation to Sociocultural Variables. Obesity Reviews. 71: 147-154.

Al-Kandari, Y.Y (2010). Change and Modernization: A Kuwaiti Family as a Model. (In Arabic) Cairo: Almaktab Aljame'e Alhadeth.

Al-Kandari, Y.Y. (2001a). Social Support and its relations to Blood pressure in Kuwaiti Family (In Arabic). Journal of the Social Science. 39(, 2), 317-345.

Al-Kandari, Y.Y. (2001b). Physical Health and its Relations to Some Sociocultural Variables in a Sample of Kuwaiti Elderly (in Arabic). Faculty of Arts Journal. Menoufis University, 47,47:, 1-26.

AlMari, T.S.K., Oei, T.P.S., \& Al-Adawi, S. (2009). The development of the short Muslim Practice and Belief Scale. Mental Health, Religion \& Culture, 12(5), 415-426.

Al-Mutairi, H (2000). Behaviour Disorder among Low Income Kuwaiti Family Children. Jounal of Social Sciences. 28(3): 65-88.

Arcury, T.A., Stafford J.M., Bell, R.A., Golden, S.L., Snively, B.M., \& Quandt, S.A. (2007). The association of health and functional status with private and public religious practice among rural, ethnically diverse, older adults with diabetes. J Rural Health, 23(3),: 246-53.

Ashkanani, H.R. (2009). The relationship between religiosity and subjective well-being: A Case of Kuwaiti Car Accident Victims. Traumatology, 15(1), 23-28.

Assarian, F., Biqam, H., Asqarnejad, A. (2006). An Epidemiological study of obsessivecompulsive disorder among high school students and its relationship with religious attitudes. Archives of Iranian Medicine, (9)2, $104-107$.

Barakat, H. (2008). The Contemporary Arabic Society: Experimental social research. (In Arabic). Beirut: The Arabian United Studies Center.

Baroun, K.A (2006). Relations among religiosity, health, happiness, and anxiety for Kuwaiti adolescents. Psychol Rep, 99(3), 717-22. 
Bergin, A.E., Masters, K.S., \& Richards, P.S. (1987). Religiousness and Mental Health Reconsidered: A Study of an Intrinsically Religious Sample. Journal of Counseling Psychology, 34 (2), 197-204.

Blazer, D. \& Erdman, P. (1976). Religion and aging in a longitudinal panel. The Gerontologist, 16(1), 82-85.

Blumenthal JA, Babyak MA, Ironson G, Thoresen C, Powell L, Czajkowski S, Burg M, Keefe FJ, Steffen P, Catellier D (2007). Spirituality, religion and clinical outcomes in patients recovering from an acute myocardial infarction. Psychosomatic Medicine, 69, 501-508

Braam, A.W., Hein, E., Deeg, D.J., Twisk, J.W., Beekman, A.T., Van Tilburg, W. (2004). Religious involvement and 6-year course of depressive symptoms in older Dutch citizens: results from the Longitudinal Aging Study Amsterdam. J Aging Health, 16(4), 467-89.

Burisch, M. (1984). You don't always get what you pay for: Measuring depression with short and simple versus long and sophisticated scales. Journal of Research in Personality, 18, 81-98.

Burisch, M. (1997). Test length and validity revisited. European Journal of Personality, 11, 303-315.

Campbell, A., Philip, C., \& Willard, R. (1976). The quality of American life: Perceptions, evaluations, and satisfactions. New York: Russell Sage Foundation.

Chaaya, M., Sibai, A.M., Fayad, R., and\& El-Roueiheb, Z. (2007). Religiosity and depression in older people: evidence from underprivileged refugee and non-refugee communities in Lebanon. Aging Ment Health, 11(1), 37-44.

Chida, Y. \& Steptoe, A. (2008). Positive Psychological Well-Being and Mortality: A Quantitative Review of Prospective Observational Studies. Psychosomatic Medicine, 70, 741-756.

Chida, Y., Steptoe, A. \& Powell (2009). Religiosity/spirituality and mortality. A systematic quantitative review. Psychother Psychother, 78(2), 81-90.

Crawford, ME.; Handal, PJ; \& Wiener, RL. (1989). The relationship between religion and mental health/Distress. Review of Relioues Research, 31(1), 16-22.

Cummings, S.M., Neff, J.A., \& Husaini, B.A. (2003). Functional impairment as a predictor of depressive symptomatology: the role of race, religiosity, and social support. Health Soc Work, 28(1), 23-32.

Dressler, William W. (1980) Coping dispositions, social supports, and health status. Ethos, 8, 146-171.

Dressler, William W. (1982b) Hypertension and Culture Change: Acculturation and Disease in the West Indies. South Salem, NY: Redgrave Publishing Co.

Dressler, William W. (1984) Hypertension and perceived stress: a St. Lucian example. Ethos, 12, 265-283.

Dressler, William W. (1985) Extended family relationships, social support, and mental health in a Southern black community. Journal of Health and Social Behavior, 26, 39-48.

Dressler, William W. (1990). Lifestyle, stress, and blood pressure in a Southern black community. Psychosomatic Medicine, 52, 182-198.

Dressler, William W. (1994), Social status and the health of families: a model. Social Science and Medicine, 39, 1605-1613.

Dressler, William W. (1999). Modernization, stress and blood pressure: New directions in research. Human Biology, 71, 583-605. 
Dressler, William W. and\& Henrietta, Bernal. (1982a). Acculturation and stress in a low income Puerto Rican community. Journal of Human Stress, 8, 32-38.

Dressler, William W. and\& James, R., \& Bindon. (1996). Social status, social context, and arterial blood pressure. American Journal of Physical Anthropology, 102, 55-66.

Francis, L, Katz, Y; Yablon, Y. \& Robbins, M (2004). Religiosity, Personality, and Happiness: A Study among Israeli Male Undergraduates. Journal of Happiness Studies, 5(4), 315-333.

Francis, L.J., Jones, S.H., \& Wilcox, C. (1997). Religiosity and dimensions of psychological well-being among 16-19 year olds. Journal of Christian Education, 40(1), 15-20.

Francis, L.J., Sahin, A. \& Al-Failakawi, F (2008). Psychometric properties of two Islamic measures among young adults in Kuwait: the Sahin-Francis Scale of Attitude toward Islam and the Sahin Index of Islamic Moral Values. Journal of Muslim Mental Health, 3(1), 9-24.

Ghorbani, N., \& Watson, P.J. (2006). Religious orientation types in Iranian Muslims: Differences in alexithymia, emotional intelligence, self-consciousness and psychological adjustment. Review of Religious Research, 47(3), 303-310.

Hadaway, C.K. (1978). Life satisfaction and religion: A reanalysis. Social Forces, 57(2), 636-643.

Hebert, R.S., Dang. Q., \& Schulz, R. (2007). Religious beliefs and practices are associated with better mental health in family caregivers of patients with dementia: findings from the REACH study. Am J Geriatr Psychiatry, 15(4), 292-300.

Hixson, K.A, Gruchow, H.W., \& Morgan, D.W. (1998). The relation between religiosity, selected health behaviors, and blood pressure among adult females. Prev Med, 27(4), 545-52.

Holt, C.L., Clark, E. M., \& Klem, P. R. (2007). Expansion and Validation of the Spiritual Health Locus of Control Scale. Journal of Health Psychology, 12 (4), 597-612.

Holt, CL., Haire-Joshu, DL., Lukwago, SN. , Lewellyn ,L \& Kreuter, MW. (2005). The Role of Religiosity in Dietary Beliefs and Behaviors Among Urban African American Women. Cancer Control, 84-90.

Hughes, J.W., Tomlinson, A., Blumenthal, J.A., Davidson, J., Sketch, M.H., \& Watkins, L.L. (2004). Social support and religiosity as coping strategies for anxiety in hospitalized cardiac patients. Ann Behav Med, 28(3), 179-85.

Jana-Masri, A., \& Priester, P.E. (2007). The development and validation of a Qura'nbased instrument to assess Islamic religiosity: The Religiosity of Islam Scale. Journal of Muslim Mental Health, 2, 177-188.

King, D.A., Lyness, J.M., Duberstein, P.R., He, H., Tu, X.M., \& Seaburn, D.B. (2007). Religious involvement and depressive symptoms in primary care elders. Psychol Med, 37(12), 1807-15. Epub 2007 May 14.

King, Donald. (1990). Religion and health relationships: A review. Journal of Religion and Health, 29(2), 101-112.

Koenig, H.G. (1998). Religious attitudes and practices of hospitalized medically ill older adults. Int J Geriatr Psychiatry, 13(4), 213-24.

Koenig, H.G. (2007). Religion and depression in older medical inpatients. Am J Geriatr Psychiatry, 15(4), 282-91.

Koenig, H.G., Siegler, I.C., \& George, L.K. (1989). Religious and non-religious coping: Impact on adaptation to later life. Journal of Religion and Aging, 5, 73-94.

Koenig, H.G.; McCullough, M.E.; and\& Larson, D.B. (2001). Handbook of religion and health. New York: Oxford University Press. 
Lester, D.,\& Abdel-Khalek, A. (2008). Religiosity and death anxiety using non-western scales. Psychol Rep, 103(3), 652.

Levin, Jeffrey A., \& Vanderpool, Harold. (1989). Is religion therapeutically significant for hypertension. Social Science Medicine, 29(1), 69-78.

Levin, J.S., \& Vanderpool, H.Y. (1989). Is religion therapeutically significant for hypertension?. Soc Sci Med., 29(1), 69-78.

Lewis, C.; Maltby, J.; \& Burkinshaw, S (2000). Religion and Happiness: still no association. Journal of Beliefs \& Values, (21)2,233-236.

Lewis, CA., Lanigan, C., Joseph, S., \& Fockert, J (1997). Religiosity and happiness: no evidence for an association among undergraduates. Person. Individ. Diff., 22(1), 119-121.

Lim, J.W., Yi, J. (2009). The effects of religiosity, spirituality, and social support on quality of life: a comparison between Korean American and Korean breast and gynecologic cancer survivors. Oncol Nurs Forum, 36(6), 699-708.

Mansour, T. (1987). A study in a psychological attitudes of some age stratum in Kuwaiti society toward elderly using proverbs. (In Arabic). Social Sciences Journal, 15(1), 69-102.

Momtaz, Y.A., Hamid, T.A. \& Yahaya, N. (2009). The Role of Religiosity on Relationship between Chronic Health Problems and Psychological Well-Being among Malay Muslim older persons. Research Journal of Medical Sciences, 3(2), 188-193.

Moreira-Almeida A, Neto FL, \& Koenig HG. (2006). Religiousness and mental health: a review. Rev Bras Psiquiatr, 28(3), 242-50.

Musick, M.A., House, J.S., Williams, D.R. (2004). Attendance at religious services and mortality in a national sample. J Health Soc Behav., 45(2), 198-213.

Mussap, A. (2009). Strength of faith and body image in Muslim and non-Muslim women. Mental Health, Religion \& Culture, 12(2), 121-127.

Nelson CJ, Rosenfeld B, Breitbart W, \& Galietta M. (2002). Spirituality, religion, and depression in the terminally ill. Psychosomatics, 43(3), 213-20.

Oleckno, W.illiam, \& Blacconiere, Michael. (1991). Relationship of religiosity to wellness and other health-related behaviors and outcomes. Psychological Report, 86, 819-826.

Oman D, Reed D. (1998). Religion and mortality among the community-dwelling elderly. Am J Public Health, 88(10), 1469-75.

Oman, D., Kurata, J.H., Strawbridge. W,J., \& Cohen R.D. (2002). Religious attendance and cause of death over 31 years. Int J Psychiatry Med, (1), 69-89.

Rew, L. \& Wong, Y.J. (2006). A systematic review of associations among religiosity/ spirituality and adolescent health attitudes and behaviors. J Adolesc Health, 38(4), 433-42.

Reyes-Ortiz, C.A., Pelaez, M., Koenig, H.G, Mulligan, T. (2007). Religiosity and selfrated health among Latin American and Caribbean elders. Int J Psychiatry Med, 37(4), 425-43.

Robbins, M. \& Francis, L.J. (1996) Are religious people happier? A study among undergraduates, in: L.J. Francis, W.K. Kay \& W.S. Campbell (Eds). Research in Religious Education, 207-217.

Seeman, T.E., Dubin, L.F., \& Seeman, M. (2003). Religiosity/spirituality and health. A critical review of the evidence for biological pathways. Am Psychol.58(1), 53-63.

Shkolnik, T., Weiner, C., Malik, L., \& Festinger, Y. (2001). The effect of Jewish religiosity of elderly Israelis on their life satisfaction, health, function and activity. $J$ Cross Cult Gerontol, 16(3), 201-19. 
Steffen, P.R., Hinderliter, A.L., Blumenthal. J.A., \& Sherwood, A. (2001). Religious coping, ethnicity, and ambulatory blood pressure. Psychosom Med, 63(4), 523-30.

Tartaro J, Luecken LJ, Gunn HE. (2005). Exploring heart and soul: effects of religiosity/ spirituality and gender on blood pressure and cortisol stress responses. J Health Psychol, 10(6), 753-66.

Thomas, C.J. (2002). The context of religiosity, social support and health locus of control: implications for the health-related quality of life of African-American hemodialysis patients. J Health Soc Policy., 16(1-2), 43-54.

Walsh, A. (1998). Religion and hypertension: testing alternative explanations among immigrants. Behav Med., 24(3), 122-30.

Walso, Anthony. (1998). Religion and hypertension: Testing alternative explanations among immigrants. Behavioral Medicine, 24, 1122-130.

Wilde, A., \& Joseph, S. (1997). Religiosity and personality in a Muslim context. Personality and Individual Differences, 23, 899-900.

Wingate, L.R., Bobadilla L, Burns AB, Cukrowicz KC, Hernandez A, Ketterman RL, Minnix J, Petty S, Richey JA, Sachs-Ericsson N, Stanley S, Williams FM, Joiner TE Jr.et al., (2005). Suicidality in African American men: the roles of southern residence, religiosity, and social support. Suicide Life Threat Behav, 35(6), 615-29.

Wong, Y.J., Rew, L. and\& Slaikeu, K.D. (2006). A systematic review of recent research on adolescent religiosity/spirituality and mental health. Issues Ment Health Nurs., 27(2), 161-83.

Yeager, D.M., Glei, D.A., Au, M., Lin, H.S., Sloan, R.P., \& Weinstein, M. (2006). Religious involvement and health outcomes among older persons in Taiwan. Soc Sci Med, 63(8), 2228-41.

Yeung, W. J. \& Chan, Y. (2007). "The Positive Effects of Religiousness on Mental Health in Physically Vulnerable Populations: A Review on Recent Empirical Studies and Related Theories." International Journal of Psychosocial Rehabilitation 11( 2), 3752. [Online at: www.psychosocial.com/IJPR_11/Positive_Effects_of_Religiousness_Yeung_Jerf.html.]

Yohannes, A.M., Koenig, H.G., Baldwin, R.C., \& Connolly, M.J. (2008). Health behaviour, depression and religiosity in older patients admitted to intermediate care. Int J Geriatr Psychiatry, 23(7), 735-40.

Yoon, D.P. (2006). Religiousness/Spirituality, Social Support, Life Satisfaction, and Depression Among Diverse Minority Elderly. 4th Annual Gero-Ed Forum, February 16-19, 2006, Chicago, IL.

\section{Acknowledgment}

This study was funded by Kuwait University (SO 03/04). The author would like to thank Kuwait University for its support. Also, the author would like to thank elderly department and Mobile Care Unit at Ministry of social affairs in Kuwait for their support. 